\title{
Battery Measurement Methods and Artificial Intelligence Applied in Energy Management Systems
}

\author{
J. MENYHÁRT ${ }^{1}$, R. SZABOLCSI ${ }^{2}$ \\ ${ }^{1}$ University of Debrecen, Faculty of Engineering, Department of Mechanical Engineering, \\ jozsef.menyhart@eng.unideb.hu \\ º́buda University, Donát Bánki Faculty of Mechanical and Safety Engineering, Institute of Mechatronics and \\ Vehicle Engineering, Department of Mechatronics, szabolcsi.robert@bgk.uni-obuda.hu
}

Abstract. Diagnostics of batteries using advanced methods have gained remarkable roles in the past few years. This study focuses on the type of measurements, tests and methods to reveal and classify them. During manufacturing and operation several faults could emerge in batteries including non-optimal operation conditions, operators without experience, and finally, random changes in batteries under physical and nonphysical conditions. Improper handling of batteries and battery cells man cause operation failures or, in the worst case, accidents. To reveal these problems several methods are applied in industry and in scientific laboratories. For a comprehensive analysis of battery management, artificial intelligence and Industry 4.0 methods can be used very effectively. Big Data analysis in its standard form is not a new achievement, but other mathematical tools could be applied to control monitoring such as Fuzzy Logic or Support Vector Machine (SVM). They are efficient tools to analyse the deviation of batteries condition because it can detect sudden changes, parameter deviations and anomalies, and the user's behaviour and habits. This article gives a description about the most important battery testing methods and the connection between Big Data and Operation Management with Artificial Intelligent (AI) methods.

\section{Introduction}

Pokorádi et al. used the so-called envelope methods to reveal local faults in technical systems [1]. Failure Mode and Effect Analyses and Fuzzy Logic were applied [1] [2]. To analyse the risk of a technical system, the ideal sets of Fuzzy rules were difficult to identify. Some studies applied other soft computing methods to identify faults and optimize technical systems. [3] Vibration measurement is a powerful method to detect failures in mechanical systems [4-7]. Tóth et al. determined the fault of sensors and measuring methods and optimized them in their works [8-11].

Due to its flexibility and computational efficiency, several studies applied Fuzzy analysis to check operation parameter [12] [13]. Fuzzy logic is a perfect tool for fault feature extraction. These applications were presented [1]. Machine learning methods for optimization of parameters such as support vector machines were used by Mankovits et al. [3] Combination of Fuzzy logic, Support Vector Machine (SVM) and Big Data System for extraction of defect problems in operation of technical systems may be a crucial part of industrial life. The principles of Industry 4.0 were the base of these research projects. [14] The authors will summarize the most important analysis methods available and 
proper for battery technical status measurements, emphasizing the importance of Big Data and Artificial Intelligence in fleet and/or energy management systems.

\section{Battery Measurement Methods}

Recently most of the vehicles, logistic equipment and smart devices have been working on electrical energy stored batteries. Technical information of batteries including lifespan and other physical and chemical properties have paramount importance for users. These properties and technical information may give feedback about the efficiency or the performance of batteries. Manufacturers are to produce batteries with the highest efficiency and safety level. Users intend to use their equipment with the longest lifespan ensured by manufacturers. In the following chapters we can catch a glimpse of the most important battery measurement methods and safety rules.

\subsection{Indirect Measurements of Batteries}

Battery or its cell parameters can be measured directly by the necessary measurement methods and tools. This traditional method is not always usable. Sometimes charge is left in batteries, State of Charge (SoC) can be determined by full discharge of the battery and measuring energy output, it takes time in life, it wastes energy in the form of dissipated heat energy, each test cycle shortens battery life and it may not be practical if the battery is in use. The remaining lifespan of a secondary cell can be determined by continuous cycling of charge-discharge process until it fails. However, there are no prior data about the real cell lifespan expectation. This is State of Health (SoH) of the battery. All we have to use in practice are very simple tests. [15]

\subsubsection{State of Charge - SoC}

Energy might be left in the batteries compared to the energy it had before being charged or recharged. In other words, it gives the user indication how longer batteries will continue to work before it needs to be recharged. This method is able to describe the short-term capability of the batteries. SoC can show the available electrical charge of battery, which is often expressed in a percentage of the maximum battery charge available. SoC reference will include the rated capacity of the new battery or battery cell rather than the current capacity of the battery. Cell capacity reduces due to the aging of the cell, at the end of the lifespan of cell, the capacity of the batteries will only be $80 \%$ of its rated capacity. The temperature and discharge rate may have an effect on the effective capacity of the batteries. [16]

\subsubsection{State of Health $-\mathrm{SoH}$}

State of Health is a special type of measurement. It shows the general conditions of the batteries and it is an ability to deliver the required electrical power compared to a new battery. SoH is not an absolute measurement, it can define a long-term capability of the battery and it can serve as an indication parameter. It can describe how much of the available lifespan energy of the battery has been used, and how much charge is left inside. In practice we can compare it to odometer. It indicates the number of kilometres travelled since the vehicle was new. Important to know: battery manufacturers do not specify SoH properties or numbers, because they supply new batteries rather than second hand ones. 
SoH can be applied after batteries started their lifespan either on the shelf or when they entered into service. SoH definitions are therefore specified by test equipment manufacturers or by users. [17]

\subsection{Test Conditions and Qualification of Testing}

This chapter looks into the details of tests in a general aspect. Test conditions must be specified, repeatable, their results may be obtained, and meaningful comparisons may be concluded. This fact includes such factors as method, temperature, DOD (Depth of Discharge), load and duty cycle. [15]

Qualification testing is crucial in practice if batteries are used in critical application. These comprehensive tests are carried out initially on a few cells, including tests of some of them subjected to their destruction, if necessary. In the second step we can find tests about battery cell packs before the products are approved by the customers. During these tests, cells have to meet the manufacturer's specifications. Manufacturers also use test to check the cells to arbitrary limits set to determine how long the cells survive under unusual loads. These tests are important to define the failure modes and/or safety factors. Batteries must be tested with the recommended charger to check the compatibility. Manufacturers have to analyse the users' habit and behaviour to avoid overcharged batteries. [15]

\subsubsection{Mechanical Testing}

Mechanical tests are thoroughly defined and described in different safety standards. These tests contain several simple tests starting with dimensional accuracy and finishing with dynamic testing to verify that the product can survive any static and/or dynamic mechanical load being normal or, abnormal both in a static or dynamic aspect. [15] Test rig of the mechanical test of the battery can be seen in Fig. 1. [18].

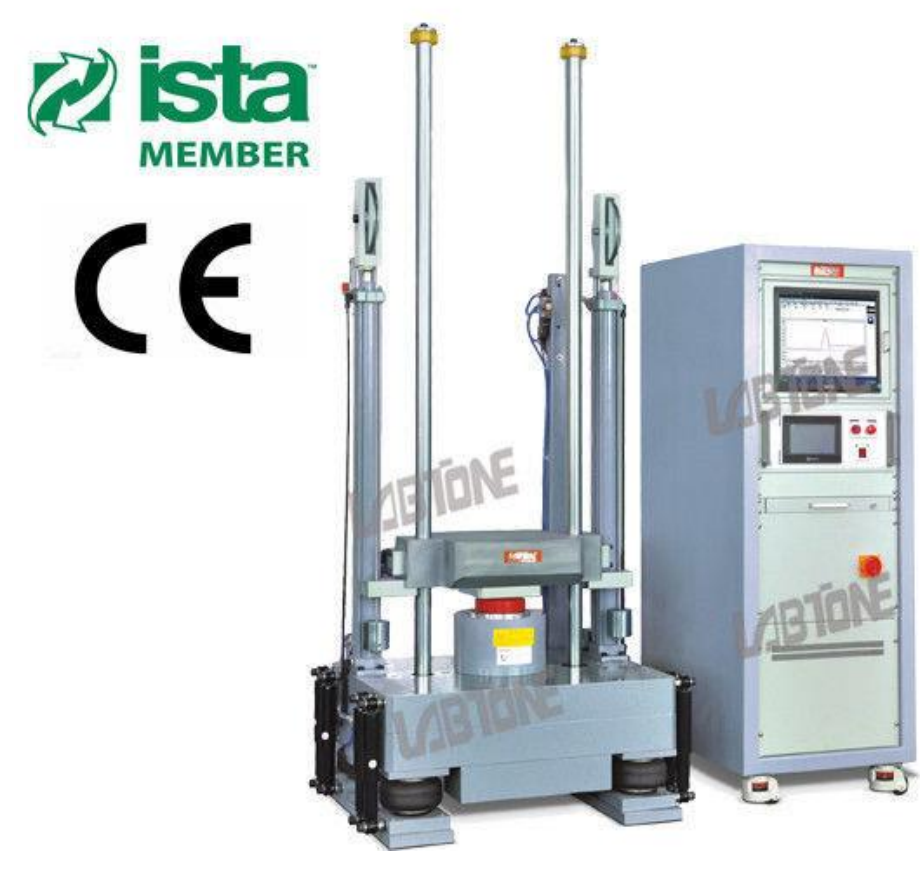

Figure 1. Battery mechanical test [18] 


\subsubsection{Environmental Testing}

Environmental tests are carried out to expose the product to all the environmental conditions including temperature, pressure, humidity etc. The test branch of the environmental analysis can be seen in Fig. 2. [15]

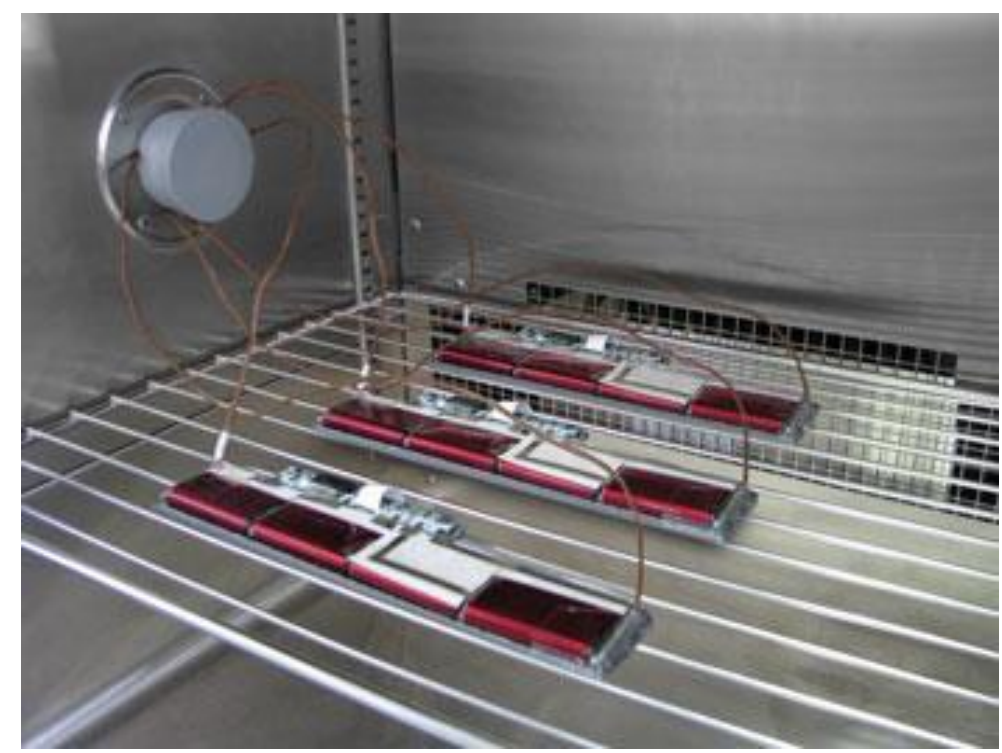

Figure 2. Battery environmental test [19]

\subsection{Cycle and Load Testing}

Cycle and load tests are among the most important ones of the qualification tests. Battery cells are subjected to the repeated charge and discharge cycles to verify that the cells meet the manufacturer's or the customer's requirements. Lifecycle is defined as the number of charge and discharge cycles battery can perform before its nominal capacity is under $80 \%$ of its initial rated capacity. These tests are necessary to verify that the battery performance is in parallel with the finished product's property. [15]

'Temperature, charge/discharge rates and Depth of Discharge play important role in the cycle life of the cells. Depending on the purpose of the tests, temperature and DOD should be controlled at an agreed reference level in order to have repeatable results which can be compared to a standard. Alternatively, tests can be used to simulate operating conditions in which the temperature is allowed to rise, or DOD is restricted, to determine how the cycle life will be affected. Generally, it takes about 5 hours for a controlled full charge discharge cycle. Testing 1000 cycles will take 208 days assuming 7 working days per week with 24 hours per day.' [15]

Load testing is used to verify that the battery can deliver its specified electrical power when given applications are required. 


\subsection{Thermal Imaging}

Thermal Imaging is a very important diagnostic equipment in maintenance programs. Battery manufacturers use it during battery test, as well. Thermal imaging is used to find hot spots on batteries. These hot spots can indicate the points of highest thermal stresses. Thermal imaging is a special photographic technique which records the intensity of the infra-red radiation emission.

These thermal pictures can help to identify failures such as overheating, inadequate heat sinking, air flow, undersized current conductors and interference from consecutive battery cells or other electrical devices. The images can also be used to determine the best location for the temperature sensors used to protect the health of the circuits and battery cells. [15]

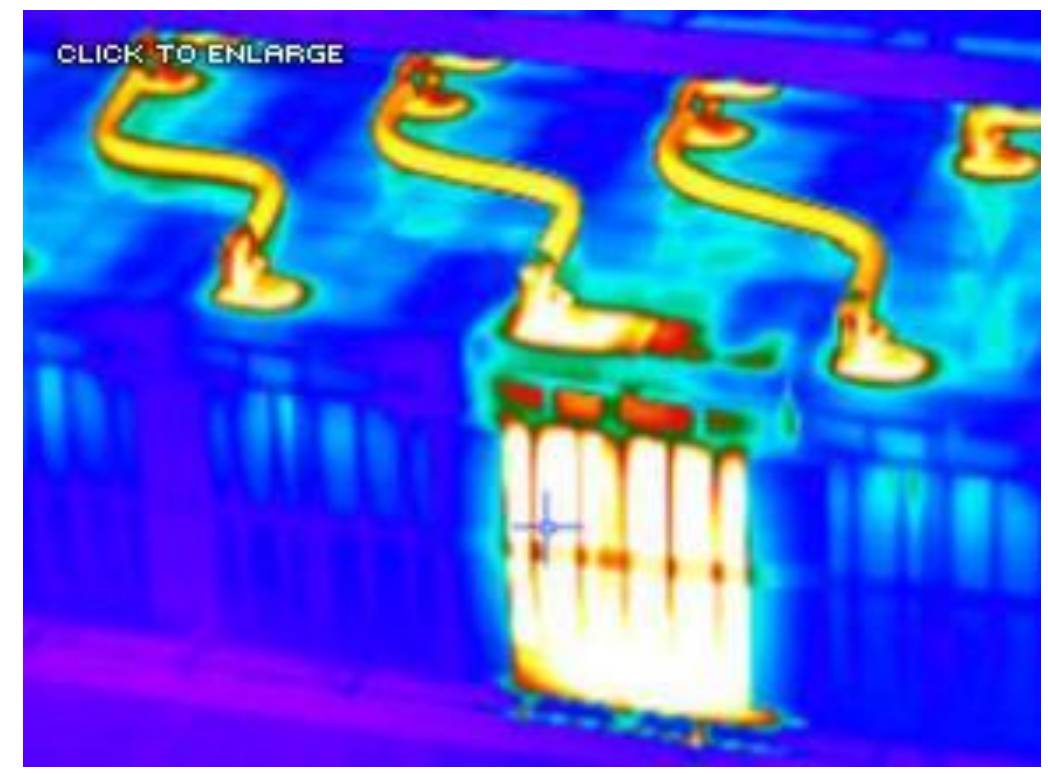

Figure 3. Battery Thermal test [20]

\subsection{Electromagnetic Compatibility (EMC) testing}

Electromagnetic compatibility (EMC) is the ability of electronic and electrical equipment and systems to operate without adversely affecting other electrical or electronic equipment, such as interference of lightning, noises generated by rotating electrical machines, digital pulses, power line transients, radio frequency (RF) signals etc. The tests of EMC would occur in an environment without other sources of EMC. This usually means an anechoic chamber or a Faraday cage, and, a special wide range signal sources and sensitive receivers are needed to generate and measure the interference features and properties. [15]

\subsection{Performance Monitoring}

Performance monitoring is used to certify whether the battery cells continue to perform as required once they are in use in the application for which they were specified. These are individual tests specified by users, these measurements are not standard measurements. There are no simple direct measurements. [15] 


\subsection{Failure Analysis Methods}

Cell failure analysis is made by manufacturers. Manufacturers must check the batteries mechanical and chemical components. These kinds of tests must use analytical equipment, such as electron microscopes and mass spectrometers. [15]

\section{Safety Standards}

Batteries must comply with national and/or international Safety Standards required by the safety organizations (e.g. UL, ANSI, CSA and IEC standards) of the countries where the products are sold. Table 1 contains the most important and widely used safety parameters. [15]

Safety Test [15]:

- Casing:
- Strength, rigidity and flammability
- Mould stress (Temperature)
○ Venting
$\circ$ Insulation
- Electrolyte without pressure
○ No leakage
○ No explosion or fire risk

- Failsafe Electronics:
○ Marking
- Instruction for use
- Safety instructions

- Protection from or tolerance to
- Short circuit
- Overcharge (time)
- Overcharge (voltage)
- Over-discharge
- Voltage reversal
- High temperature
- Low temperature
- Misuse
○ Abuse

- Mechanical tests
- Crush tests
- Nail penetration tests
- Shock test
- Vibration test
- Impact test 
○ Drop test

- Environmental Tests

$\circ$ Heating

○ Temperature cycling

○ Altitude

- Humidity

- Exposure to fire

- Power output - Load test

\section{Big Data and Artificial Intelligence Applied in Energy}

\section{Management Systems}

It is widely known that global electrical energy industry has a high-level of pressure to cut carbon emissions. These organizations intend to use new methods to manage the increasing demands expressed in gigawatts of unpredictable, weather-dependent renewable (wind energy, solar energy) energy flowing on electrical power grids. These energy saving methods and the new environmental rules have high priority at a political level. [21] [22]

Several new researches are devoted to use Artificial Intelligence to manage data flow in integrated electrical energy grids.

Artificial Intelligence proposed solutions of enterprises and researchers and can support decision makers more efficiently than before. AI can be used to manage electricity plants by briefly switching off power demand across communities or regions. For the analyses, researchers and governments have to create Big Data system with necessary amount of the data analysed under different conditions. [21] [22] Electrical energy management is a very popular scientific topic and needed to be solved for the traffic and logistic problems and challenges, too.

The previous chapters show measurement methods available to analyse the performance of batteries. Now, the focus of researchers and engineers is on how they can expand the lifespan limits of batteries to get a better efficiency. Our vision is that soft computing methods and AI can show the new way, which is - in many cases - undiscovered, for the researchers to answer questions put before. [21] [22]

\section{Conclusions}

The authors introduced measurement techniques used in design and maintenance of batteries. The authors highlighted few types of the battery measurement methods widely used by manufacturers and users of batteries. All types of measurements are important for the manufacturers to define the ideal technical parameters for the batteries. Measurements are necessary tools to determine technical parameters of the batteries. Voltage range of the batteries defined by allowed maximums and allowed minimum voltages, is a critical point, for instance, for vehicle accessibility, and it has importance also in logistic applications ranging from performance to safety aspects.

Future work of the authors is strongly connected to possible extension the range of the of batteries expressed with maximum and minimum voltages of the batteries to allow their deeper discharges with 
considerations of the safety regulations. The possible proposed method introduced and used by the authors will be based on soft computing methods.

\section{Acknowledgement}

The publication is supported by the EFOP-3.6.1-16-2016-00022 project. The project is co-financed by the European Union and the European Social Fund.

\section{References}

[1] L. Pokorádi (2008) Rendszerek és folyamatok modellezése. Campus Kiadó, Debrecen. ISBN 978963-9822-06-1

[2] D. Duminica - M. Avram - T. C. Apostolescu (2011) Fuzzy Logic Used in FMEA Analysis, The Romanian Review Precision Mechanics. Optics \& Mechatronics. 39 pp. 37-40.

[3] T. Mankovits - T. Szabó - I. Kocsis - I. Páczelt (2014) Optimization of the Shape of Axi-Symmetric Rubber Bumpers. Strojniski vestnik-Journal of Mechanical Engineering. 60 (1) pp. 61-71.

[4] D. Bodnár - S. Hajdu (2018) Párhuzamos kinematikájú manipulátorok kinematikájának és munkaterének vizsgálata $=$ Kinematics and Workspace analysis of parallel manipulators . INTERNATIONAL JOURNAL OF ENGINEERING AND MANAGEMENT SCIENCES / MÚSZAKI ÉS MENEDZSMENT TUDOMÁNYI KÖZLEMÉNYEK. 3(2) pp. 1-5.

[5] A. Szántó - S. Hajdu (2018) Járművek menetdinamikai szimulációja Matlab/Simulink környezetben = Vehicle dynamics simulation in Matlab/Simulink environment. INTERNATIONAL JOURNAL OF ENGINEERING AND MANAGEMENT SCIENCES / MÚSZAKI ÉS MENEDZSMENT TUDOMÁNYI KÖZLEMÉNYEK. 3(2) pp. 36-41.

[6] S. Hajdu - P. Gáspár (2017) Robust Control of Single-Mast Stacker Cranes. ACTA POLYTECHNICA HUNGARICA. 14(4) pp. 105-119.

[7] S. Hajdu - P. Gáspár (2016) Reducing the Mast Vibration of Single-Mast Stacker Cranes by GainScheduled Control. INTERNATIONAL JOURNAL OF APPLIED MATHEMATICS AND COMPUTER SCIENCE. 26(4) pp. 791-802.

[8] K. Sipos - J. Tóth (2017) Elektropneumatikus szelepek áramlási veszteségének mérése ipari eszközökkel = Measurement of friction losses of electro-pneumatical valves with industrial devices INTERNATIONAL JOURNAL OF ENGINEERING AND MANAGEMENT SCIENCES / MÜSZAKI ÉS MENEDZSMENT TUDOMÁNYI KÖZLEMÉNYEK. 2 (1) pp. 68-72.

[9] V. Ács, J. Tóth (2017) Test Station for Reed Sensors and Inductive Proximity Switches. ANNALS OF THE UNIVERSITY OF ORADEA FASCICLE OF MANAGEMENT AND TECHNOLOGICAL ENGINEERING. 16 (2) pp. 99-104. 
[10] L. C. A. Meiga - J. Tóth (2016) Control and Position Memory of a TTR Robot. ANNALS OF THE UNIVERSITY OF ORADEA FASCICLE OF MANAGEMENT AND TECHNOLOGICAL ENGINEERING. 25 (2) pp. 115-118.

[11] J. Tóth - X. E. Tóth (2015) How to Control a Pneumatical and an Electrical Driven Linear. ANNALS OF THE UNIVERSITY OF ORADEA FASCICLE OF MANAGEMENT AND TECHNOLOGICAL ENGINEERING. 24 (1) pp. 185-188.

[12] D. Arias - J.M. Sanchez - J.M. Zurita (2005) Applying Fuzzy logic to Operations Management Research. EUSFLAT - LFA 2005 pp. 88-93.

[13] O. A. Shaneb - P.C. Taylor - G. Coates (2012) Real time operation of $\mu$ CHP systems using fuzzy logic, Energy and Buildings. 55. pp. 141-150.

[14] G. Husi G. (2016) Ipar 4.0, jegyzet. University of Debrecen, Faculty of Engineering.

[15] Electropaedia: Battery and Energy Technologies, Battery Testing. url: https://www.mpoweruk.com/testing.htm (Downloaded: 2018.11.10. 14:54)

[16] Electropaedia: Battery and Energy Technologies, State of Charge (SoC) Determination. url: https://www.mpoweruk.com/soc.htm (Downloaded: 2018.11.10. 15:12)

[17] Electropaedia: Battery and Energy Technologies, State of Health (SoH) Determination. url: https://www.mpoweruk.com/soh.htm (Downloaded: 2018.11.10. 15:13)

[18] Labtone Test Equipment CO., LTD: 100kg Payload Mechanical Shock Tester ,Battery Shock Impact Testing Machine. url: http://www.vibrationtestmachine.com/sale-8719959-100kg-payloadmechanical-shock-tester-battery-shock-impact-testing-machine.html (Downloaded: 2018.11.10. $15: 48)$

[19] Espec Quality is more than a word: Battery Testing Chambers. url: https://www.espec.com/na/chamber_faq/answer/battery_testing (Downloaded: 2018.11.10. $15: 49)$

[20] Infrared Imaging Services LLC: Infrared Electrical Inspection Services. url: http://www.infraredimagingservices.com/electrical-infrared (Downloaded: 2018.11.10. 15:45)

[21] hackernoon.com, Steven Hansen: How Big Data Is Improving AI and Machine Learning? url: https://hackernoon.com/how-big-data-is-empowering-ai-and-machine-learning-4e93a1004c8f (Downloaded: 2018.11.10. 16:02)

[22] World Economic Forum: Here's how AI fits into the future of energy, url: https://www.weforum.org/agenda/2018/05/how-ai-can-help-meet-global-energy-demand (Downloaded: 2018.11.10.16:03) 